\title{
Atrial fibrillation ablation and mitral regurgitation
}

\section{(CVjekoslav Radeljić*}

University Hospital Centre "Sestre milosrdnice", Zagreb, Croatia
RECEIVED:

May 1, 2018

ACCEPTED:

May 10, 2018

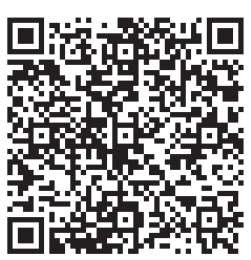

KEYWORDS: ablation, mitral regurgitation, cryoablation.

CITATION: Cardiol Croat. 2018;13(5-6):180. | https://doi.org/10.15836/ccar2018.180

*ADDRESS FOR CORRESPONDENCE: Vjekoslav Radeljić, Klinički bolnički centar Sestre milosrdnice, Vinogradska 29, HR-10000 Zagreb, Croatia. / E-mail: vjekoslav.radeljic@gmail.com

ORCID: Vjekoslav Radeljić, https://orcid.org/0000-0003-2471-4035

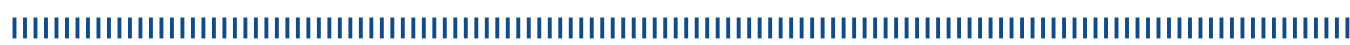

Pulmonary vein electrical isolation using radiofrequency RF energy or cryoablation is a standard in modern atrial fibrillation treatment. In the first place this method is a treatment of choice for those patients with paroxysmal pattern of this most frequent arrhythmia. Furthermore, patients with more prominent symptoms gain best response on the treatment considering quality of life in the first place. On the other side treatment of persistent and permanent forms of arrhythmia from the perspective of benefit from catheter ablation is still not well established ${ }^{1}$.

Mitral regurgitation changes atrial hemodynamics and structural characteristics. In case of functional mitral regurgitation this change in atrial architectonics with mitral annulus dilatation is obvious.

Surgical mitral regurgitation treatment changes occurrence and appearance of atrial fibrillation. Surgical incision and a scar tissue creates slow conduction isthmuses as a new arrhythmia substratum, predominantly for re-entry arrhythmias. On the other side, reduction of mitral regurgitation has desirable effect ${ }^{2}$

Mechanic mitral valve raises difficulties for cardiologist during the procedure since catheter can stuck in it.

Since patients with mitral regurgitation and atrial fibrillation are often surgically treated there is a question whether surgical maze procedure or catheter ablation of atrial fibrillation is better ${ }^{3}$. Earlier studies gave advantage to surgical treatment. However those studies were in time when modern ablation techniques have not been widely used.

Atrial fibrillation and mitral regurgitations remain accompanied and we can expect more and more patients with two diseases.

However, treatment requires special expertise and should be individualized by united efforts form arrhythmologists and valvular experts.

LITERATURE IIIIIIIIIIIIIIIIIIIIIIIIIIIIIIIIIIIIIIIIIIIIIIIIIIIIIIIIIIIIIIIIIIIIIIIIIIIIIIIIIIIIIIIIIIIIIIIIIIIIIIII

1. Gertz ZM, Raina A, Mountantonakis SE, Zado ES, Callans DJ, Marchlinski FE, et al. The impact of mitral regurgitation on patients undergoing catheter ablation of atrial fibrillation. Europace. 2011 Aug;13(8):1127-32. https://doi.org/10.1093/europace/eur098

2. Zhao L, Jiang W, Zhou L, Gu J, Wang Y, Liu Y, et al. The role of valvular regurgitation in catheter ablation outcomes of patients with long-standing persistent atrial fibrillation. Europace. 2014 Jun;16(6):848-54. https://doi.org/10.1093/europace/eut252

3. McGann C, Akoum N, Patel A, Kholmovski E, Revelo P. Damal K, et al. Atrial fibrillation ablation outcome is predicted by left atrial remodeling on MRI. Circ Arrhythm Electrophysiol. 2014 Feb;7(1):23-30. https://doi.org/10.1161/CIRCEP.113.000689 